TESL A | VOL. 21 | NO. 2 | OKTOBER 2019|

\title{
Reposisi dan Penggantian Menara Transmisi 150 kV
}

\author{
Juara Mangapul Tambunan ${ }^{1}$ \\ Sekolah Tinggi Teknik -PLN Jakarta \\ Email: juaramangapult_stmsi@yahoo.com \\ Hary Mulyono ${ }^{1}$ \\ Sekolah Tinggi Teknik -PLN Jakarta \\ Email: juaramangapult_stmsi@yahoo.com
}

\begin{abstract}
S:Transmission line is a very absolute thing in an electric power system. In the distribution of electricity from generating centers to loads (consummers), where the distance is quite far it is done through the transmission line. Transmission channels those are generally used based on construction are the lattice type and steel pole. The transmission channel has a safe limit against other objects around it according to the standard set. The air transmission line uses a TACSR (Thermal Aluminium Conductor Steel Reinforce) conductor which has a working capacity with temperatures up to $150^{\circ} \mathrm{C}$. Based on calculations when the distance is $212 \mathrm{~m}$ with a temperature of $150^{\circ} \mathrm{C}$ the value of the roof is $9,40 \mathrm{~m}$. When the distance is $173 \mathrm{~m}$ with a temperature of $150^{\circ} \mathrm{C}$ the maximum value of the roof is $7.8 \mathrm{~m}$. When The condition of the temperature and the length of the span affect the value of the roof the greater of the temperature and the length of the span, so the greater of the resistance.
\end{abstract}

Keyword: Transmission line;TACSR; value of the roof

ABSTRAK:Saluran transmisi adalah suatu hal yang sangat mutlak dalam suatu sistem tenaga listrik. Dalam penyaluran tenaga listrik dari pusat-pusat pembangkit ke beban (konsumen), dimana jaraknya cukup jauh maka dilakukan lewat saluran transmisi. Saluran transmisi yang umum digunakan berdasarkan konstruksinya adalah tipe lattice dan steel pole. Saluran transmisi ini memiliki batas aman terhadap obyek lain yang ada di sekitarnya sesuai standar yang ditetapkan. Saluran transmisi udara menggunakan konduktor jenis TACSR (Thermal Aluminium Conductor Steel Reinforced) yang memiliki kemampuan kerja dengan suhu sampai $150^{\circ} \mathrm{C}$. Berdasarkan perhitungan pada saat jarak span $212 \mathrm{~m}$ dan dengan suhu $150^{\circ} \mathrm{C}$ andongan maksimumnya bernilai $9,40 \mathrm{~m}$. Pada saat jarak $173 \mathrm{~m}$ dan dengan suhu $150^{\circ} \mathrm{C}$ andongan maksimalnya $7,8 \mathrm{~m}$. Pada saat jarak $233 \mathrm{~m}$ dengan suhu $150^{\circ} \mathrm{C}$ andongan maksimumnya adalah $10,58 \mathrm{~m}$. Keadaan suhu dan panjang span mempengaruhi nilai andongan, semakin besar suhu dan panjang span maka nilai andongan akan semakin besar.

Kata Kunci: Nilai andongan;Saluran transmisi;TACSR

\section{PENDAHULUAN}

$\mathrm{P}$ embangunan jalan tol enam ruas Jakarta saat ini sedang giat dilaksanakan. Dalam waktu dekat pembangunannya akan dilakukan dikawasan Kelapa Gading-Pulogadung yang sebagian jalur jalan tol tersebut lintasannya berpotongan (crossing) dengan jaringan transmisi PLN $150 \mathrm{kV}$. Dititik perpotongan tersebut, jarak antara kawat konduktor dengan jalan tol (Clearance) tidak memenuhi ketentuan yang berlaku.

Sebagai konsekuensinya, tower PLN di seksi tersebut perlu direlokasi atau ditambah ketinggiannya agar kawat konduktor yang menghubungkan tower tersebut memenuhi persyaratan standar. Oleh sebab itu, masalah relokasi tower dan peninggian clearance tersebut perlu dikaji untuk mendapatkan solusi terbaik.

Masalah non teknis dan administratif yang menimbulkan atau menyebabkan hambatan dalam merealisasikan proyek ini, seperti pembebasan tanah, masalah dampak lingkungan dan sebagainya belum sepenuhnya dipertimbangkan dalam kajian ini. Adapun tujuan dan manfaat penelitian ini adalah untuk mengetahui bagaimana cara penanganan masalah pada tower transmisi yang terdampak pembangunan jalan tol, dan mengetahui nilai andongan pada tower transmisi. Peneliti mendapat beberapa studi literatur berdasar pedoman penelitian ini.

\section{TINJAUAN PUSTAKA}

Dalam penelitian ini adalah menganalisis dan mengimplementasikan sebuah metode yang digunakan untuk melakukan penanganan masalah tower yang terdampak tol dan peninggian clearance. Peneliti telah melakukan beberapa studi literatur sebagai pedoman penelitian ini.

Herman Said (2007) telah melakukan penelitian tentang "Menghitung andongan kawat penghantar transmisi $150 \mathrm{kV}$ ". Penelitian dilakukan terhadap dua macam tower yaitu; tower transmisi sama tinggi dan tower transmisi tidak sama tinggi. Berdasarkan penelitian yang dilakukan, andongan pada tower tidak sama tinggi lebih kecil daripada tower sama tinggi.

Ahmad Sopian (2005), telah melakukan penelitian tentang "Rencana relokasi tower pada Saluran

\footnotetext{
${ }^{1}$ Sekolah Tinggi Teknik -PLN Jakarta
} 
Udara Tegangan Tinggi $150 \mathrm{kV}$ ". Penelitian dilakukan untuk mengganti posisi tower dan tipe isolator suspension ke tension.

Hari Anna (2009) telah melakukan penelitian tentang "Analisis andongan dan kuat tarik Saluran Udara Tegangan Tinggi $150 \mathrm{kV}$ “. Penelitian ini dilakukan untuk menganalisa andongan dan kuat tarik saluran udara $150 \mathrm{kV}$.

\subsection{Transmisi Tenaga Listrik}

Transmisi tenaga listrik merupakan proses penyaluran energi listrik dari pembangkit tenaga listrik (Power Plant) hingga substation distribution sehingga dapat disalurkan sampai pada pengguna listrik melalui suatu bahan konduktor

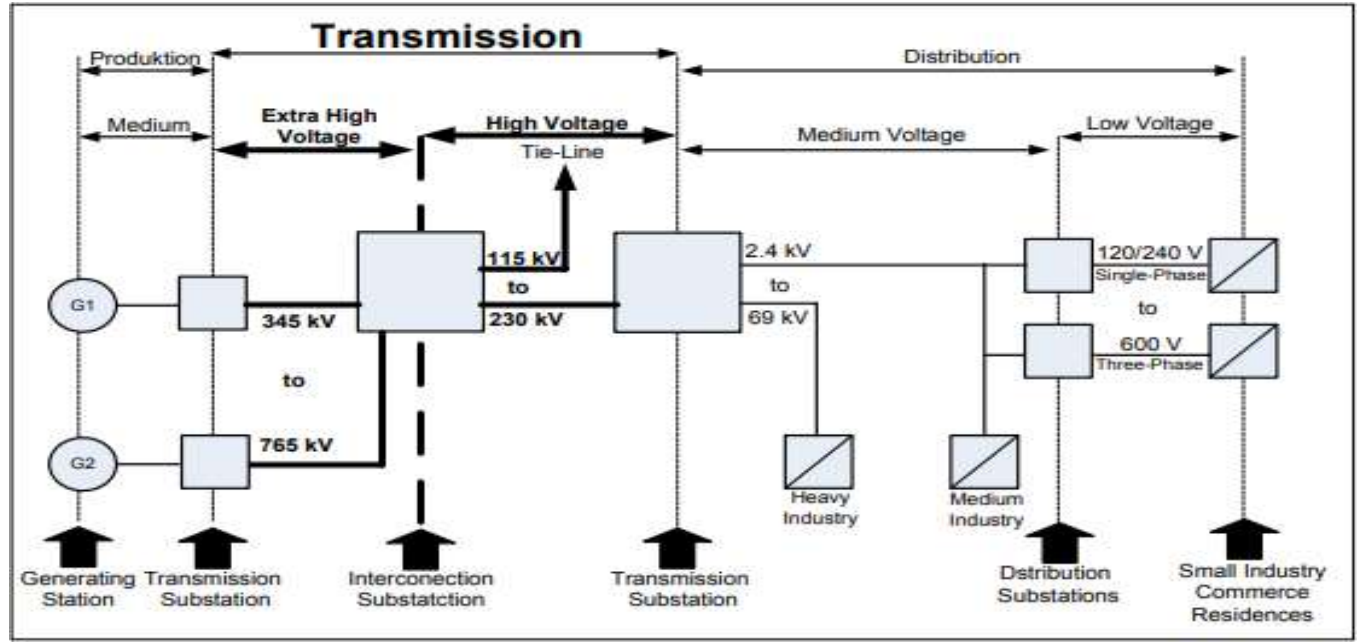

- Gambar 1. Diagram Blok Umum Sistem Tenaga Listrik

Gambar diatas menunjukkan blok diagram dasar dari sistem transmisi dan distribusi tenaga listrik yang terdiri dari dua stasiun pembangkit (generating station) G1 dan G2, beberapa substation yaitu hubungan antar substation (interconnecting substation) dan untuk bagian komersial perumahan (commercial residential), dan industrial loads. Transmisi berada pada bagian yang diberi arsir tebal. Fungsi dari bagian transmission substation menyediakan servis untuk merubah dalam menaikkan dan menurunkan tegangan pada saluran tegangan yang ditransmisikan serta meliputi regulasi tegangan. Standarisasi range tegangan internasional yaitu $345 \mathrm{kV}$ hingga $765 \mathrm{kV}$ untuk Saluran Tegangan Ekstra Tinggi dan $115 \mathrm{kV}$ hingga $230 \mathrm{kV}$ untuk Saluran Tegangan Tinggi. Standarisasi tegangan transmisi listrik di Indonesia adalah $500 \mathrm{kV}$ untuk Saluran Ekstra Tinggi dan $150 \mathrm{kV}$ untuk Saluran Tegangan Tinggi.

Distribution Substation, pada bagian ini merubah tegangan aliran listrik dari tegangan medium menjadi tegangan rendah dengan transformator step-down, dimana memiliki tap otomatis dan memiliki kemampuan untuk regulator tegangan rendah. Tegangan rendah meliputi rentangan dari 120/240V single phase sampai $600 \mathrm{~V}$ three phase. Bagian ini melayani perumahan, komersial dan institusi serta industri kecil. Interconnecting substation, pada bagian ini untuk melayani sambungan percabangan transmisi dengan power tegangan yang berbeda serta untuk menambah kestabilan pada keseluruhan jaringan. Setiap substation selalu memiliki Circuit Breakers, Fuses, lightning arresters untuk pengaman peralatan. Antara lain dengan penambahan peralatan kontrol, pengukuran, switching, pada setiap bagian substation. Energi listrik yang ditransmisikan didesain untuk Extra High Voltage (EHV), High Voltage (HV), Medium Voltage (MV), dan Low Voltage ( LV).

\subsection{Jenis saluran transmisi}

Jenis saluran transmisi tenaga listrik terdapat dua macam, yaitu saluran kabel (under ground cable) atau SKTM (Saluran Kabel Tegangan Menengah) dan saluran udara atau SUTM (Saluran Udara Tegangan Menengah).

\subsubsection{Saluran Kabel}

Kabel bawah tanah biasanya terdiri atas satu atau lebih konduktor dengan lapisan pelindung berupa material isolasi. 
Saluran Kabel Tegangan Tinggi (SKTT) 150 kV milik PLN dalam kondisi normal menggunakan tekanan antara 130 - 140 psi. Saluran transmisi dengan menggunakan kabel dapat diklasifikasikan berdasarkan letaknya yaitu underground atau kabel bawah tanah dan submarine atau kabel bawah laut.

\subsubsection{Saluran Udara}

Daya listrik dihasilkan oleh generator yang umumnya disebut pembangkit. Komponen penyaluran yang berfungsi menyalurkan energi listrik dari pembangkit menuju konsumen umumnya disebut transmisi. Saluran transmisi merupakan elemen yang penting dalam sistem tenaga untuk menyalurkan daya aktif dan daya reaktif dari sisi sumber sampai sisi konsumen.

\subsubsection{Bagian-bagian Saluran Transmisi}

\subsubsection{Konduktor Penghantar}

Kawat penghantar berfungsi untuk mengalirkan arus listrik dari suatu tempat ke tempat yang lain. Jenis kawat penghantar yang biasa di gunakan pada saluran transmisi adalah tembaga dengan konduktivitas $100 \%(\mathrm{Cu} \mathrm{100 \% )}$, atau aluminium dengan konduktivitas $61 \%$ (Al 61\%). Kawat penghantar tembaga memiliki beberapa kelebihan dibandingkan kawat penghantar aluminium karena konduktivitas dan kuat tariknya tinggi. Tapi kelemahannya adalah untuk besar tahanan yang sama tembaga lebih berat dari aluminium, dan lebih mahal. Oleh karena itu kawat aluminium menggantikan kedudukan pemakaian tembaga. Bahan konduktor yang dipergunakan untuk saluran energi listrik perlu memiliki sifat-sifat, yaitu : konduktivitas yang tinggi, kekuatan tarik mekanik yang tinggi, berat jenis yang rendah, ekonomis, lentur dan tidak mudah patah. Biasanya konduktor pada SUTT-SUTET merupakan konduktor berkas (stranded) atau serabut yang dipilin, agar mempunyai kapasitas yang lebih besar dibanding konduktor pejal dan mempermudah dalam penanganannya. Klasifikasi konduktor berdasarkan bahannya :

a. Konduktor jenis tembaga BC (Barecopper)

Konduktor ini merupakan penghantar yang baik karena memiliki konduktivitas tinggi dan kekuatan

mekanik yang cukup baik. konduktor

b. Konduktor jenis aluminium Konduktor dengan bahan aluminium lebih ringan daripada

jenis tembaga, konduktivitas dan kekuatan mekaniknya lebih rendah. Jenis-jenis konduktor alumini-

um antara lain :

b.1. Konduktor ACSR (Alumunium Conductor Steel Reinforced)

Konduktor jenis ini, bagian dalamnya berupa steel yang mempunyai kuat mekanik yang tinggi, sedangkan bagian luarnya berupa aluminium yang mempunyai konduktivitas yang tinggi. Karena sifat elektron lebih menyukai bagian luar konduktor daripada bagian sebelah dalam konduktor, maka pada sebagian besar SUTT maupun SUTET menggunakan konduktor jenis ACSR. Untuk daerah yang udaranya mengandung kadar belerang tinggi dipakai jenis ACSR, yaitu konduktor jenis ACSR yang konduktor steelnya dilapisi dengan aluminium.

\section{b.2. Konduktor jenis TACSR (Thermal Aluminium Conductor Steel Reinforced)}

Pada saluran transmisi yang mempunyai kapasitas penyaluran / beban sistem tinggi maka dipasang konduktor jenis TACSR. Klasifikasi konduktor menurut konstruksinya ada dua macam, yang pertama dinamakan kawat padat (solid wire) adalah kawat tunggal yang padat (tidak berongga), dan berpenampang bulat, jenis ini hanya dipakai untuk penampang-penampang yang kecil, karena penghantar-panghantar yang berpenampang besar sukar ditangani serta kurang flexible. Yang kedua adalah kawat rongga (hollow conductor), kawat berongga yang dibuat untuk mendapatkan garis tengah luar yang besar.

\subsubsection{Isolator Padat (Insulator)}

Isolasi padat (insulator) adalah media penyekat antara bagian yang bertegangan dengan yang tidak bertegangan atau ground secara elektrik dan mekanik. Pada SUTT \& SUTET, insulator berfungsi untuk mengisolir konduktor fasa dengan tower/ground. Sesuai fungsinya, insulator yang baik harus memenuhi sifat :

a. Karakteristik Elektrik

Insulator mempunyai ketahanan tegangan impuls petir pengenal dan tegangan kerja, tegangan 
tembus minimum sesuai tegangan kerja dan merupakan bahan isolasi yang diapit oleh logam sehingga merupakan kapasitor. Kapasitansinya diperbesar oleh polutan maupun kelembaban udara di permukaannya. Apabila nilai isolasi menurun akibat dari polutan maupun kerusakan pada insulator, maka akan terjadi kegagalan isolasi yang akhirnya dapat menimbulkan gangguan.

\section{b. Karakteristik Mekanik}

Insulator harus mempunyai kuat mekanik guna menanggung beban tarik konduktor penghantar maupun beban berat insulator dan konduktor penghantar. Insulator menurut material ada dua macam :

\section{b.1. Insulator keramik (porselen \& gelas)}

\section{b.1.1. Insulator Porselen}

Insulator porselen mempunyai keunggulan tidak mudah pecah, tahan terhadap cuaca. Dalam penggunaannya insulator ini harus di glasur. Warna glasur biasanya coklat, dengan warna lebih tua atau lebih muda. Hal itu juga berlaku untuk daerah dimana glasur lebih tipis dan lebih terang, sebagai contoh pada bagian tepi dengan radius kecil. Daerah yang di glasur harus dilingkupi glasur halus dan mengkilat, bebas dari retak dan cacat lain.

\section{b.1.2. Insulator Gelas}

Digunakan hanya untuk insulator jenis piring. Bagian gelas harus bebas dari lubang atau cacat lain termasuk adanya gelembung dalam gelas. Warna gelas biasanya hijau, dengan warna lebih tua atau lebih muda. Jika terjadi kerusakan insulator gelas mudah dideteksi.

\section{b.2. Insulator non-keramik (komposit)}

Insulator non-keramik (komposit) terbuat dari bahan polimer. Insulator komposit dilengkapi dengan mechanical load-bearing fiberglass rod, yang diselimuti oleh weather shed polimer untuk mendapatkan nilai kekuatan elektrik yang tinggi. Komponen utama dari insulator komposit yaitu : Endfittings, Coronaring(s), Fiberglass-reinforced plasticrod, Interface between shed and sleeve, Weathershed.

Insulator Menurut Bentuk :

a. Insulator piring ; dipergunakan untuk insulator penegang dan insulator gantung, dimana jumlah pi-

ringan insulator disesuaikan dengan tegangan sistem.

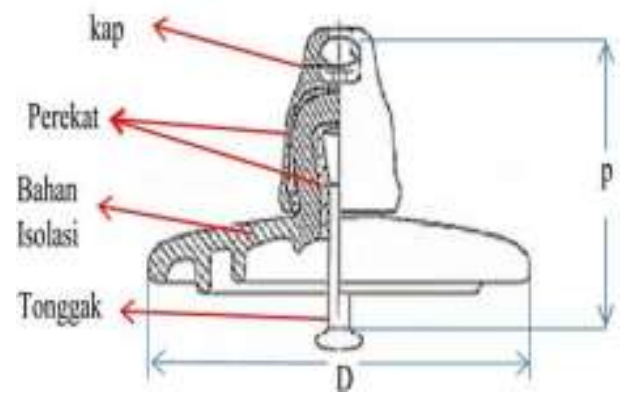

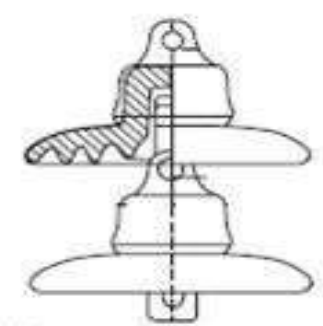

(a)

Gambar 3. Insulator piring (a) tipe clevis (b) tipe ball-and-socket

b. Insulator Tipe-Post; digunakan sebagai tumpuan dan memegang bagi konduktor diatasnya untuk pemasangan secara vertikal dan sebagai insulator dudukan. Biasanya terpasang pada tower jenis po- le atau pada tiang sudut. Digunakan untuk memegang dan menahan konduktor untuk pemasangan 
secara horizontal.

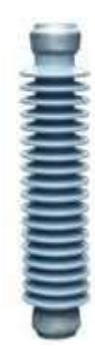

Gambar 4. Insulator Tipe Post

\subsubsection{Jarak Antar Kawat}

Jarak antar kawat konduktor dipengaruhi oleh beberapa hal, terutama hal mekanis dari kawat konduktor. Bahan material dan diameter konduktor harus diperhatikan dalam perhitungan, karena untuk konduktor yang kecil, khususnya yang terbuat dari aluminium, memiliki berat yang lebih ringan, sehingga jika terdapat tekanan angin akan lebih mengayun secara vertikal dibandingkan dengan konduktor dengan luas penampang yang lebih besar dan bahan yang lebih berat. Biasanya konduktor akan mengayun secara sinkron dengan angin, tetapi untuk span yang panjang dan kawat yang kecil, ada kemungkinan konduktor mengayun dengan tidak sinkron, dan ukuran konduktor serta andongan maksimum pada titik tengah span adalah faktor yang harus diperhitungkan dalam menentukan jarak antar kawat konduktor.

\subsubsection{Jarak Clearance Tower}

Clearance kawat konduktor dengan obyek-obyek lainnya berdasarkan SNI 04-0918-2002, adalah sebagai berikut :

Tabel 1. Jarak clearance dengan objek lain

\begin{tabular}{|c|l|l|}
\hline No & Lokasi & $150 \mathrm{kV}$ \\
\hline 1 & Lapangan Terbuka/Daerah Terbuka & 8,5 meter \\
\hline 2 & Daerah dengan keadaan tertentu & 13,5 meter \\
\hline 2.1 & Bangunan tidak tahan api & 5 meter \\
\hline 2.2 & Bangunan tahan api & 9 meter \\
\hline 2.3 & Lalu Lintas atau Jalan Raya, Rel Kereta Api Biasa & 5 meter \\
\hline 2.4 & Pohon Pada Umumnya, Hutan dan Perkebunan & 13,5 meter \\
\hline 2.5 & Lapangan Olahraga Umum & 4 meter \\
\hline 2.6 & $\begin{array}{l}\text { SUTT lainnya, SUTR, SUTM, Jaringan Telekomunikasi, } \\
\text { Antena Radio, Televisi, dan Kereta Gantung }\end{array}$ & $\begin{array}{l}4 \text { meter } \\
\text { Tembatan Besi, Besi Penahan Penghantar, Kereta Listrik }\end{array}$ \\
\hline 2.8 & $\begin{array}{l}\text { Titik Tertinggi Tiang Kapal Pada Kedudukan Air Pasang } \\
\text { atau Tertinggi Pada Lalu Lintas Air }\end{array}$ & 4 meter \\
\hline
\end{tabular}

\subsubsection{Jenis-Jenis Tower Transmisi}

Menurut fungsinya, menara/tower listrik dibagi tujuh macam, yaitu

a. Dead End Tower

yaitu tiang akhir yang berlokasi didekat gardu induk, tower ini hampir sepenuhnya menanggung gaya tarik. 
b. Section Tower

yaitu tiang penyekat antara sejumlah tower penyangga dengan sejumlah tower penyangga lainnya karena alasan kemudahan saat pembangunan (penarikan kawat).

c. Suspension Tower yaitu tower penegang. Tower ini hampir sepenuhnya menanggung daya berat, umumnya tidak mempunyai sudut belokan.

d. Tension Tower

yaitu tower penegang. Tower ini menanggung gaya tarik yang lebih besar dari pada gaya berat, umumnya mempunyai sudut belokan.

e. Transposition Tower

yaitu tower tension yang digunakan sebagai tempat melakukan perubahan posisi kawat

fasa guna memperbaiki impedansi transmisi.

f. Gantry Tower

yaitu tower berbentuk portal digunakan pada persilangan antara dua saluran transmisi.

g. Combined Tower operasinya.

yaitu tower yang digunakan oleh dua buah saluran transmisi yang berbeda tegangan

Menurut konstruksinya, jenis menara/tower listrik dibagi empat macam, yaitu pada gambar konstruksinya seperti terlihat sebagai berikut :

1. Lattice Tower

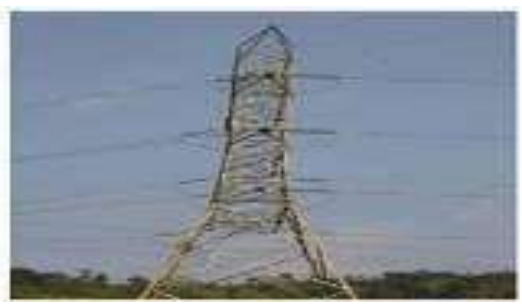

- Gambar 5. Tiang Saluran Lattice Tower

\section{Tubular Steel Pole}

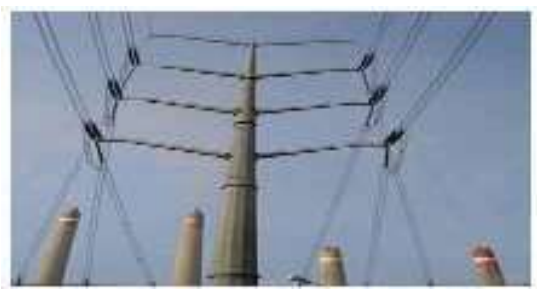

- Gambar 6. Tubular Steel Pole

\section{Wooden Pole}

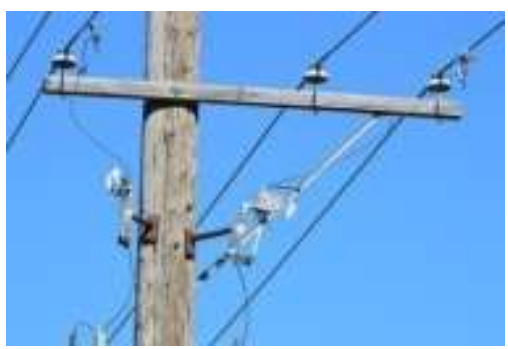

- Gambar 7. Tiang Saluran Wooden Pole

\section{METODE PENELITIAN}

Penelitian ini menggunakan metode kuantitatif, disajikan dalam bentuk angka-angka dalam proses penghitungan dan penganalisasi hasil penelitian. Lokasi penelitian di PT. Indopower Internasional. Observasi lapangan dilakukan selama empat bulan mulai dari 4 Februari sampai dengan 31 Mei 2019. Penelitian ini bertujuan menangani masalah penggantian tower transmisi $150 \mathrm{kV}$ terdapat dua variabel, yaitu: Variabel independen, merupakan variabel mempengaruhi atau yang menjadi sebab perubahan. Pada penelitian kali ini variabel independennya terkait pembangunan jalan tol yang melintasi atau trace right of way (ROW) melalui saluran udara tegangan tinggi $150 \mathrm{kV}$, dan Variabel dependen, merupakan variabel yang dipengaruhi atau menjadi akibat perubahan. Pada penelitian kali ini variabel dependennya yaitu jarak clearance antara permukaan jalan tol dengan saluran udara tegangan tinggi 150 $\mathrm{kV}$. 
Pengumpulan data pada penelitian ini dilakukan dengan wawancara dengan beberapa pegawai bagian jaringan, dan mencari sumber referensi dari berbagai buku, jurnal dan internet sebagai pendukung dalam penelitian ini, serta mengamati secara langsung dilapangan untuk memperoleh data yang diperlukan.

\subsection{Perancangan Penelitian}
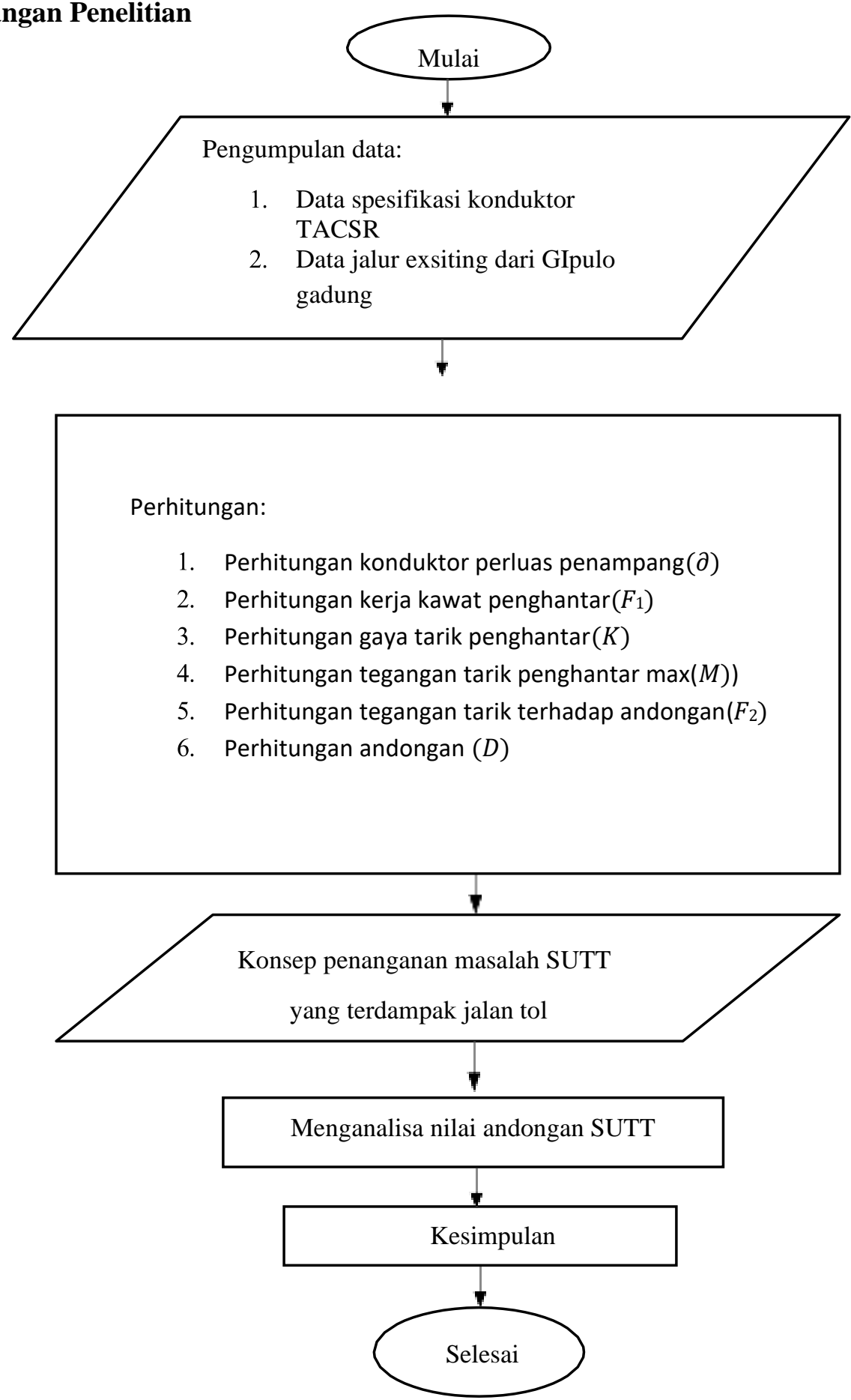

- Gambar 8. Diagram alur penelitian

Dua jenis yang terakhir yaitu concrete pole dan wooden pole tidak dipertimbangkan untuk dipilih karena jarang bahkan belum digunakan dikalangan PT PLN (Persero). Dengan demikian hanya jenis "Lattice Tower" dan Tubular Tower atau "Steel Pole" yang akan dievaluasi penggunaannya dalam 
Penelitian ini. Pemilihan dilakukan dengan metode peringkat atau "Rangking" sebagaimana dengan prosedur dibawah ini. Kriteria penilaian diantaranya adalah :

a). Aspek kebutuhan luas tanah : Setiap jenis tower memerlukan luas tanah yang berbeda. Perbedaan tersebut adalah menentukan mudah tidaknya lokasi yang diinginkan dapat digunakan.

b). Aspek pengawasan pelaksanaan konstruksi : Tower bentuk rangka (Lattice Tower) tidak memerlukan pengawasan ketat dalam pelaksanaan pemasangannya, sedangkan monopole memerlukan keahlian dan ketelitian dalam proses pemasangannya.

c). Angkutan ke lokasi : Tingkat kemudahan pengangkutan material tower berbeda antara lattice tower dengan monopole. Pada tipe lattice, struktur tower terdiri dari potongan-potongan profil baja siku, sedangkan pada monopole terdiri dari potongan yang lebih panjang dan besar, berbentuk pipa. Oleh sebab itu sebaiknya monopole dipasang pada lokasi dekat dengan jalan karena pengangkutannya memerlukan kendaraan truk.

d). Kemudahan pelaksanaan konstruksi : Kemudahan pelaksanaan dinilai berdasarkan kebutuhan alat kerja. Pada umumnya, monopole harus dipasang memerlukan crane sehingga menggunakan jalan masuk ruang gerak bagi alat berat yang luas.

\subsection{Tegangan Tarik Pada Penghantar}

Penghantar yang digunakan harus cukup aman dalam menyalurkan tenaga listrik. Untuk itu daya kerja maksimum pada kawat harus ditambahkan dengan faktor keamanan 2,2 untuk kawat tembaga tarikan keras (hard drawn) dan 2,5 untuk kawat TACSR serta kawat-kawat lainnya. Bila tarikan sehari-hari pada kawat besar, maka penghantar mudah menjadi letih karena getaran. Hal ini perlu diperhatikan dalam mempertimbangkan kekuatan kerja maksimum.

\subsection{Parabolis Andongan dan Kuat Tarik}

Untuk menentukan tegangan tarik kawat digunakan rumus :

$$
F 22=\{F 1+(K-\alpha t E)\}=M .
$$

Untuk mencari andongan (D) digunakan rumus :

$$
\mathrm{D}=\frac{\partial_{q 2} S^{2}}{8 F_{2}}
$$

Untuk mencari koefisien tegangan tarik $(\mathrm{K})$ digunakan rumus :

$$
\mathrm{K}=\mathrm{F}_{1}-\frac{\left(\partial_{q_{1}}\right)^{2} S^{2} E}{F_{1}{ }^{2}}
$$

Untuk mencari berat konduktor per luas penampang, rumusnya :

$$
\partial=W / A
$$

Untuk mencari tegangan kerja kawat penghantar digunakan rumus :

$$
F_{1}=T / A
$$

Dimana :

$F_{1}=$ Tegangan kerja kawat penghantar $\left[\mathrm{kg} / \mathrm{mm}^{2}\right]$

$\mathrm{F}_{2}=$ Tegangan tarik terhadap andongan $\left[\mathrm{kg} / \mathrm{mm}^{2}\right]$

$\mathrm{t}=$ Suhu maksimum pada andongan tertentu $\left[/{ }^{\circ} \mathrm{C}\right]$

$\mathrm{E}=$ Koefisien elastisitas penghantar $\left[\mathrm{kg} / \mathrm{mm}^{2}\right]$

$\mathrm{K}=$ Koefisien tegangan tarik $\left[\mathrm{kg} / \mathrm{mm}^{2}\right]$

$\mathrm{M}=$ Tegangan tarik kawat $\left[\mathrm{kg} / \mathrm{mm}^{2}\right]$

$\mathrm{D}=$ Andongan $[\mathrm{m}]$

$\mathrm{d}=$ Berat konduktor per luas penampang $\left[\mathrm{kg} / \mathrm{mm}^{2}\right]$

$\mathrm{q}_{2}=1,37$ untuk ke tegangan maksimum

$\mathrm{q}_{1}=1$ untuk menghitung andongan

$\mathrm{S}=$ Panjang span $[\mathrm{m}]$

$\mathrm{W}=$ Berat penghantar per satuan panjang $[\mathrm{kg} / \mathrm{m}]$

$\mathrm{A}=$ Luas penampang penghantar $\left[\mathrm{mm}^{2}\right]$ 


\section{HASIL DAN PEMBAHASAN}

4.1. Data Karakteristik Kawat Penghantar

Adapun beberapa data-data didapat :

- Merk

: TACSR

- Diameter

: $28,50 \mathrm{~mm}$

- Luas penampang

: $410 \mathrm{~mm}^{2}$

- Berat kawat

- Jarak rata-rata span

$: 1,6 \mathrm{~kg} / \mathrm{m}$

: $300 \mathrm{~m}$

- Koefisien ekspansi linear

$: 2 \times 10^{-6}$

- Koefisien elastisitas konduktor

: $6300 \mathrm{~kg} / \mathrm{mm}^{2}$

- Faktor keamanan

- Temperatur

: 2,5 untuk ke tegangan maksimum

: Maksimum $150^{\circ} \mathrm{C}$

: Minimum $20^{\circ} \mathrm{C}$

: Sehari-hari $15^{\circ} \mathrm{C}$

- Tegangan tarik kerja maksimum $\quad: 13878 \mathrm{~kg}$

\subsection{Kondisi Lokasi Terdampak Jalan Tol}

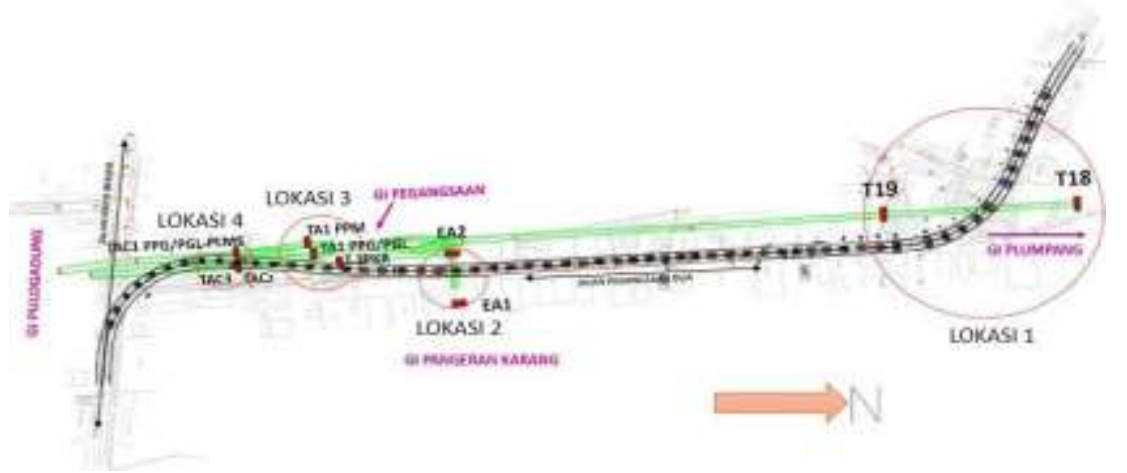

- Gambar 9. Lokasi yang terdampak jalan tol

Kondisi lokasi 1 : Tower T-18 dan T-19

Koordinat GPS : T-18 (06 $09^{\prime} 55.90^{\prime \prime} \mathrm{LS}$ dan $106^{\circ} 54^{\prime} 59.95$ ”BT)

T-19 (06¹0'08.6'LS dan 10655'00.9'BT)

Batas-batas Tapak Tower :

Tower T-18: Utara : Bangunan

Timur : Bangunan Selatan

: Pagar Halaman

Barat : Bangunan

Tower T-19: Utara : Jalan Raya

Timur : Rumah penduduk

Selatan : Rumah penduduk

Barat : Rumah Tinggal

Kondisi lokasi 2 : Tower T-EA1 dan T-EA2

Koordinat GPS : EA1 $\left(06^{\circ} 10^{\prime} 35.60^{\prime \prime}\right.$ LS dan $106^{\circ} 55^{\prime} 12.17^{\prime \prime B T) E A 2 ~(06 ² ~} 10^{\prime} 36.62^{\prime \prime}$ LSdan $106^{\circ} 55^{\prime} 4.12 " \mathrm{BT}$ )

Batas-batas Tapak Tower :

Tower T-EA1 : Utara : Jalur hijau

Timur : GI Astra Selatan

: Tanah kosong

Barat : Jalan masuk 
Tower T-EA2 : Utara : Perumahan

Timur : Jalan

Selatan : Jalan

Barat : Perumahan

Kondisi lokasi 3 : Tower di depan GI Pegangsaan

Koordinat GPS : T.3PKR $\left(06^{\circ} 10^{\prime} 43.70 " L S\right.$ dan $\left.106^{\circ} 55^{\prime} 4.49 " B T\right)$

Batas-batas Tapak Tower :

Tower di depan GI Pegangsaan : Utara : GI Pegangsaan

Timur : GI Pegangsaan

Selatan : GI Pegangsaan

Barat : GI Pegangsaan

Kondisi lokasi $4: 3$ (Tiga) Tower antara Pier P9.35 dan P9.36

Koordinat GPS : T.AC1PGS/PGD-PLMS (06 $10^{\prime} 50.31^{\prime \prime L S}$ dan $\left.106^{\circ} 55^{\prime} 4.02^{\prime \prime E}\right)$

T.AC2 $\left(06^{\circ} 10^{\prime} 50.40^{\prime \prime} \mathrm{S}\right.$ dan $\left.106^{\circ} 55^{\prime} 5.13 " \mathrm{E}\right)$

T.AC3 (06 ${ }^{\circ} 10^{\prime} 50.13^{\prime \prime S}$ dan $\left.106^{\circ} 55^{\prime} 4.90^{\prime \prime} \mathrm{E}\right)$

Batas-batas Tapak Tower : Dikelilingi rumah penduduk dari semua arah.

\subsection{Cara Menangani Masalah Clearance}

Lokasi 1 (Clearance di Atas Pier P9.2 - P9.3)

$>$ Mempertahankan tower existing T-18 danT-19.

$>$ Membangun 2 (dua) Tower Sisipan di kiri dan di kanan jalur menggunakan tower 4BB6+24 (TS-1) di sebelah barat dan 4BB6+27 di sebelah timur (TS-2),

$>$ Mengangkat konduktor dari T-18 ke T-19 melalui tower sisipan.

$>$ Menempatkan tower sisipan sedekat-dekatnya dengan jalan tol sehingga pembebasan tanah dapat dilaksanakan sekaligus bersamaan dengan pembebasan tanah yang akan dibebaskan untuk jalan tol dan tower berasal dari pemilik yang sama. Selain itu, semakin dekat letak tower dengan jalan tol, semakin hemat tinggi tower sisipan yang diperlukan.

Tipe tower sisipan adalah rangka baja dengan tinggi masing-masing 71 meter dan 74 meter.

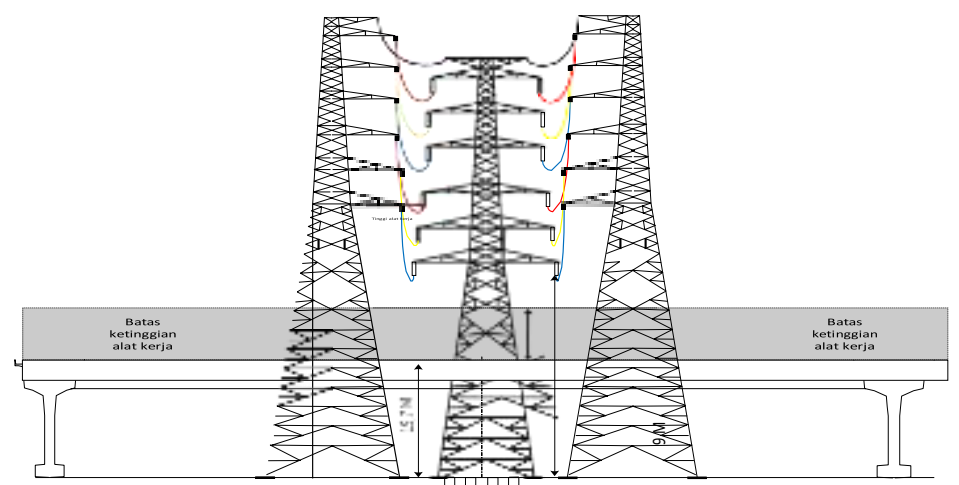

- Gambar 10. Prinsip Peninggian Clearance Konduktor T18-T19

Di Atas Pier P9.2-P9.3 Dengan 2 (Dua) Tower Sisipan

Lokasi 2 Clearance Konduktor antara T-EA1 dan T-EA2 (GI Pegangsaan ke GI Pangeran Karang)

Bentangan kawat konduktor antara GI Pegangsaan dengan GI Pangeran Karang menye-

babkan konduktor terletak di bawah jalan tol, implementasi penanganannya yaitu :

$>$ Mempertahankan tower existing T-EA1 danT-EA2.

$>$ Membangun satu tower sisipan dengan tipe Steel Pole Special+21(T-EA2A) sehingga jarak clearance konduktor memenuhi ketentuan yang berlaku

$>$ Memasang konduktor dari (EA2-A4) ke tower EA1 melalui tower sisipan

$>$ Jenis tower adalah struktur rangka baja ramping (slim latticetower) 


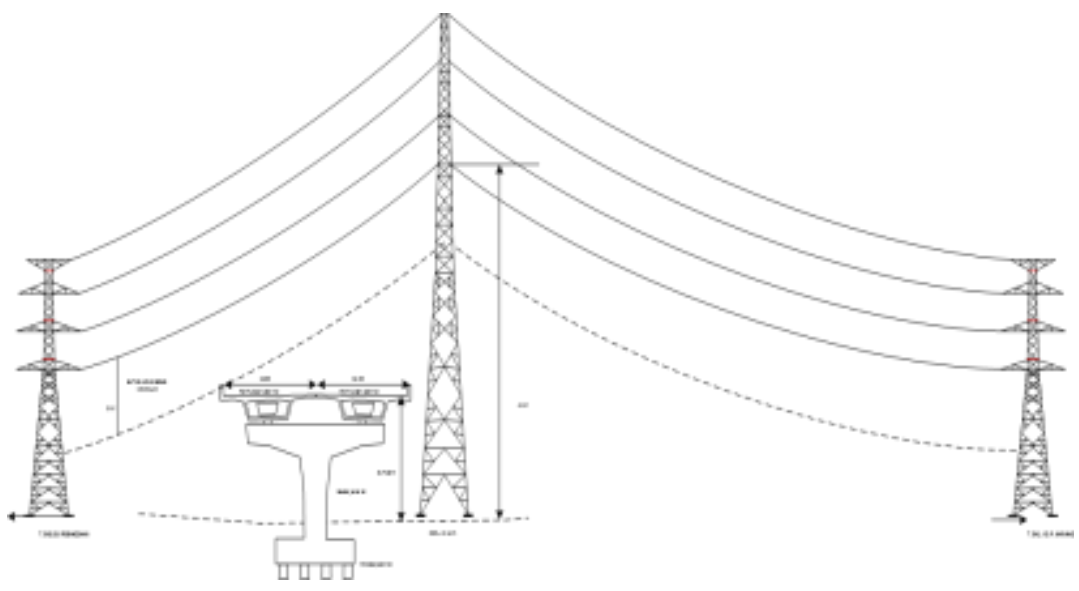

T-EA2

Tower Sisipan TS3

T-EA1

\section{Jalan Tol}

- Gambar 11. Prinsip Peninggian Clearance Konduktor dari T-EA1 ke T-EA2 di Atas Pier P9.26

Lokasi 3 Clearance Tower di GI Pegangsaan Terhadap Pier P9.31 - P9.33 Tiga buah tower di lokasi ini berada dalam jarak masing-masing yaitu :

$>$ Satu tower (T.3PKR) jarak \pm 7 meter dari Pier P9.31.

$>$ Dua tower berimpit, berada pada jarak 36 meter dan 61 meter dari Pier P9.32.

$>$ Clearance konduktor T.3PKR tidak memenuhi syarat.

Dengan permasalahan di atas, kawat konduktor di salah satu tower yang terdekat perlu dijauhkan dari arah jalan tol. Cara penanganan clearance ini adalah Mempertahankan ketiga-tiganya tower existing yaitu T.3PKR, TA1PGS/PGD dan TA1PGS-PLMS dan memindahkan konduktor ke salah satu sisi lainnya pada tower T.3PKR dimana arm telah tersedia.

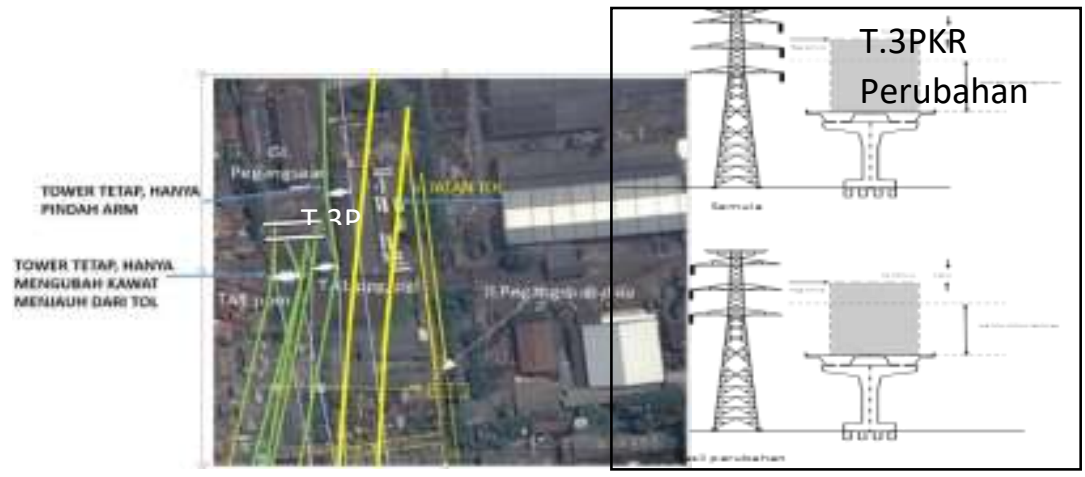

- Gambar 12. Prinsip Pemecahan Masalah Pada Tower di GI Pegangsaan

Lokasi 4 Posisi Tower Diantara Pier P9.35 dan P9.36 Tiga tower di lokasi ini berada di dalam trace jalan tol, sehingga harus dibongkar. Pe- nyelesaian masalah di lokasi ini yaitu : Membongkar 3 (tiga) tower existing, yaitu tower TAC2, TAC3, TAC1 PGS/PGS-PLMS', membangun 1 (satu) buah tower 
tambahan yaitu TN2 di sebelah barat T3, radius 50 meter, memasang kawat konduktor melalui ketiga tower pengganti tersebut. Sebagai pengaruh dari penggeseran lokasi tower, maka di sekitar Pier P9.41 dan P9.42 perlu dibangun tower tambahan dan menonaktifkan tower TAC2 Existing. Tujuannya untuk memenuhi syarat sudut tarikan kawat konduktor.

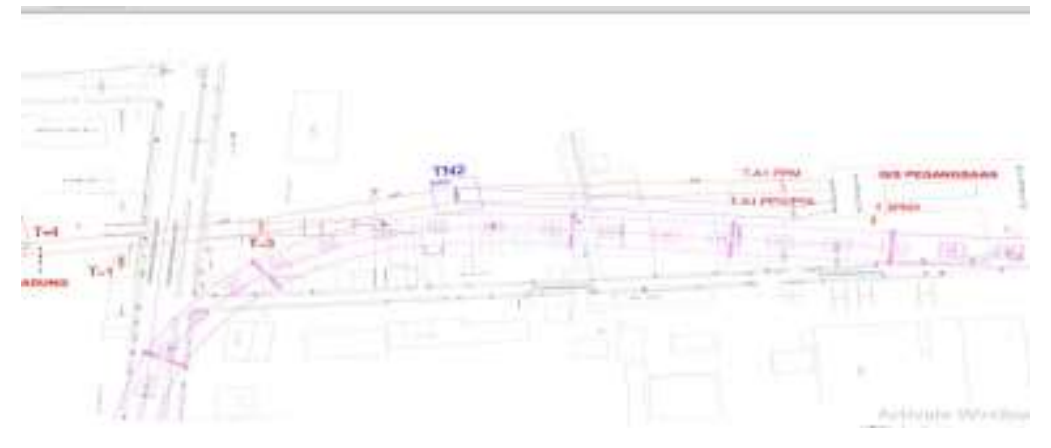

- Gambar 13. Relokasi Tower TAC2, TAC3, TAC1 PGS/PGD-PLMS

Pada Pier P9.35 dan P9.36 serta Penambahan Tower 4 cc

\subsection{Perhitungan Nilai Andongan}

Menghitung nilai andongan T-18 ke tower sisipan TS2 di lokasi 1, untuk menara yang tidak sama tinggi perhitungan dilakukan dengan panjang saluran (span) $212 \mathrm{~m}$. Rumus pendekatan yang digunakan untuk menghitung kuat tarik maksimum sama dengan rumus yang ada pada persamaan (3.1) sampai dengan (3.5). Diketahui : $\mathrm{W}=1,6 \mathrm{~kg} / \mathrm{m} ; \mathrm{S}=212$ meter ; $\mathrm{T}=13878 \mathrm{~kg}$

$$
\mathrm{A}=410 \mathrm{~mm}^{2} ; \mathrm{E}=6300 \mathrm{~kg} / \mathrm{mm}^{2} ; \mathrm{t}=150^{\circ} \mathrm{C}
$$

Ditanyakan : Mencari nilai andongan maksimum dari kawat penghantar?

Jawab : Gunakan rumus persamaan (3.2) dan (3.4)

$$
\text { Rumus (3.2) : }
$$

$$
\begin{gathered}
F_{1}=T / A=\frac{13878}{410}=33,85 \mathrm{~kg} / \mathrm{mm}^{2} \quad \mathrm{~K}=\mathrm{F}_{1}-\frac{\left(\partial q_{1}\right)^{2} S^{2} E}{F_{1}{ }^{2}} \\
-\frac{\left[\left(3,9 \times 10^{-3}\right)(1)\right]^{2}(212)^{2}(6300)}{(33,85)^{2}} \\
\mathrm{~K}=30,09 \mathrm{~kg} / \mathrm{mm}^{2}
\end{gathered}
$$

Dari perhitungan diatas dapat dilihat bahwa untuk T-18 ke tower sisipan TS2 menara sama tinggi dengan panjang saluran (span) 212 meter yang menggunakan kawat penghantar TACSR $410 \mathrm{~mm} 2$, maka andongan maksimum sebesar 9,404 meter. Temperatur yang dipakai temperatur maksimum sebagai faktor safety untuk antisipasi jika temperatur mencapai nilai maksimum, maka saluran menara transmisi dapat bekerja dengan normal dan tidak menimbulkan bahaya bagi saluran transmisi tersebut.

Dari perhitungan yang sama juga, untuk tower T-19 bahwa untuk menara sama tinggi dengan panjang saluran (span) 173 meter yang menggunakan kawat penghantar TACSR $410 \mathrm{~mm} 2$, maka andongan 
maksimum sebesar 7,80 meter. Temperatur dipakai adalah temperature maksimum sebagai faktor safety untuk antisipasi jika temperatur mencapai nilai maksimum, maka saluran menara transmisi dapat bekerja dengan normal dan tidak menimbulkan bahaya bagi saluran transmisi tersebut.

Selanjutnya perhitungan yang sama, dilokasi 2 diperoleh bahwa untuk menara sama tinggi dengan panjang saluran (span) 233 meter yang menggunakan kawat penghantar TACSR $410 \mathrm{~mm} 2$, andongan maksimum adalah 10,58 meter. Temperatur yang dipakai adalah temperature maksimum sebagai faktor safety untuk antisipasi jika temperatur mencapai nilai maksimum, maka saluran menara transmisi dapat bekerja dengan normal dan tidak menimbulkan bahaya bagi saluran transmisi tersebut.

\section{KESIMPULAN}

Berdasarkan hasil data yang diperoleh dari hasil perhitungan dan penanganan masalah pada tower transmisi $150 \mathrm{kV}$ maka diambil kesimpulan sebagai berikut:

1. Lokasi 1, kondisi lokasi terdampak pembangunan jalan tol adalah konduktor dari tower T18-19, pada lokasi 2 kondisi lokasi terdampak pembangunan jalan tol adalah tower EA2 dan EA1, pada lokasi 3 dan 4 kondisi terdampak pembangunan jalan tol adalah tower TAC1, TAC2, TAC3, T3PKR, sehingga dibuat tower baru di lokasi 4, yaitu tower TN2.

2. Pada Lokasi 1, Clearance Konduktor dari tower T18-19, hanya 4,35 meter di atas struktur jalan tol maka solusinya adalah membangun 2 (dua) buah tower sisipan masing-masing tipe $4 \mathrm{BB}$ 6+24 (TS1) pada sisi barat dan 4 BB 6+27 (TS2) pada sisi timur, masing- masing tower hanya setengah arm pada bagian dalam. Pada Lokasi 2, Clearance Konduktor dari GI Pegangsaan ke GI Pangeran Karang hanya 2,4 meter di bawah struktur jalan tol maka solusinya adalah membangun 1 (satu) buah tower sisipan dengan tipe Steel Pole Special+21. Pada Lokasi 3, terdapat 3 (tiga) buah tower yang tertabrak trase jalan tol yaitu TAC1 PPG-PGL, TAC2 (non aktif), TAC3 (non aktif) serta terdapat konduktor yang sudah tidak bertegangan untuk jalur transmisi Pulogadung - Pangeran Karangmaka solusinya adalah membongkar 3 (tiga) tower existing, membongkar konduktor dan aksesoris pada jalur transmisi Pulogadung - Pangeran Karang yang sudah tidak bertegangan. Pada Lokasi 4 karena satu buah tower combine yaitu TAC1 PPG-PGL \& PLMS pada lokasi 3 dibongkar akibat tertabrak trase jalan tol maka perlu adanya tower pengganti maka solusinya membangun 1 (satu) tower pengganti tipe 4 CC $6+12$ untuk menjauhkan kawat penghantar terhadap jalan tol.

3. Keadaan suhu pada daerah kawat penghantar mempengaruhi andongan kawat penghantar. Semakin tinggi suhunya maka andongan akan semakin rendah, begitu sebaliknya.

\section{DAFTAR PUSTAKA}

\section{SUMBER BUKU:}

Abdul Kadir. (1998) Transmisi Tenaga Listrik, Jakarta: Universitas Indonesia.

Buku Petunjuk Operasi dan Pemeliharaan Peralatan. (1968) Untuk Saluran Udara Tegangan Tinggi (SUTT), No.2, Perusahaan Umum Listrik Negara.

Hutauruk . (1985). Transmisi Daya Listrik. Penerbit erlangga, Jakarta.

Peraturan Menteri Energi dan Sumber Daya Mineral RI. (2015) Ruang Bebas dan Jarak Bebas Minimum Pada Saluran Udara Tegangan Tinggi Untuk Penyaluran Tenaga Listrik.

PT PLN Persero. (2014). Buku Pedoman Pemeliharaan Saluran Udara Tegangan Tinggi, Jakarta.

PT PLN (Persero) SPLN 121, (1996) Konstruksi Saluran Udara Tegangan Tinggi $70 \mathrm{kV}$ dan $150 \mathrm{kV}$ dengan Tiang Beton/Baja. Jakarta : PT PLN (Persero).

Said, Herman, (2007). Menghitung Andongan Kawat Penghantar Pada Saluran Transmisi 150 kV, Universitas Mercubuana, Jakarta.

Sumarsono, Heru. (2009) Analisis Perhitungan Jarak Antar Kawat dan Clearance Saluran Transmisi Udara, Semarang : Universitas Diponegoro. 